\title{
Central Indiana STEM Talent Expansion Program: Student and Faculty Interventions
}

\author{
Stephen P. Hundley ${ }^{1}$, Charles R. Feldhaus ${ }^{1}$, Jeffrey X. Watt ${ }^{2}$, Kathleen A. Marrs ${ }^{2}$, \\ Andy Gavrin ${ }^{2}$, Howard Mzumara ${ }^{3}$ \\ ${ }^{1}$ School of Engineering and Technology, IUPUI, Indianapolis, IN - USA \\ ${ }^{2}$ School of Science, IUPUI, Indianapolis, IN - USA \\ ${ }^{3}$ Planning and Institutional Improvement, IUPUI, Indianapolis, IN - USA
}

\begin{abstract}
Funded by 5-year, \$2M grant from the National Science Foundation, the Central Indiana STEM Talent Expansion Program (CI-STEP) at Indiana University-Purdue University Indianapolis (IUPUI) is creating a pipeline of students and a campus culture change to increase the number of undergraduates obtaining Science, Technology, Engineering, and Mathematics (STEM) degrees. CI-STEP addresses initiatives needed for transforming the undergraduate STEM experience by propagating, expanding, and creating new evidence-based educational innovations in undergraduate STEM education at IUPUI.

The primary goal of the project is to employ and assess the impact of several intervention strategies focused on student success, leading to higher numbers of students graduating with STEM degrees. These interventions include: new STEM Summer Bridge Academies; strengthened articulation agreements; peer-mentoring, and academic advising support for community college transfer students; expansion of Peer-led Team Learning, Just-in-Time Teaching, and other facultyinitiated, evidence-based educational opportunities; and development and expansion of career development services and internships for undergraduates.

This paper will describe CI-STEP, including the project's purpose and progress-to-date. Specific attention will focus on ways to involve faculty in implementing, adopting, and adapting evidence-based approaches to educating STEM undergraduate students. Successful strategies, conclusions-to-date, lessons learned, and implications for replication, scalability, and sustainability will also be discussed.
\end{abstract}

\section{PROJECT CONTEXT, PURPOSE, AND SIGNIFICANCE}

The Central Indiana STEM Talent Expansion Program (CI-STEP), funded by the National Science Foundation (NSF), is creating a central Indiana pipeline and a university culture change to increase the number of students obtaining STEM degrees at Indiana University-Purdue University Indianapolis (IUPUI). IUPUI is located in downtown Indianapolis, and is the state's only urban research university, with 22 schools offering over 200 degree programs. IUPUI has a national reputation for its involvement with the City of Indianapolis and the Indianapolis public school systems through the IUPUI UCASE center (Urban Center for the Advancement of STEM Education). Created in 1969 by Indiana legislators, IUPUI embodies the unorthodox partnership between Indiana and Purdue Universities to serve the educational needs in the largest metropolitan region of the state, representing one-fifth of the state's population. IUPUI has grown substantially in its 45 -year history, becoming the third largest campus in the state, and is the only 4-year public institution of higher education in this region. More than $60 \%$ of IUPUI's 30,100 students are first-generation college attendees and $16 \%$ of its student body belongs to minority groups.

CI-STEP is based in two IUPUI academic units: The School of Science and the School of Engineering and Technology. These are two of the three largest undergraduate schools by headcount at IUPUI, and both schools award Purdue University degrees. Together the two schools are known as leaders in undergraduate STEM education. Both schools have leadership roles in implementation of Project Lead the Way (Engineering and Bio-Medical Sciences) in school districts state-wide, and faculty from both schools are principle investigators of the Indiana-STEM Resource Network.

The CI-STEP project addresses initiatives needed for transforming undergraduate STEM education by propagating, expanding, and creating new research-based educational innovations in undergraduate STEM education at IUPUI. The primary goal of this project is to employ and assess the impact of several intervention strategies on student success, leading to higher numbers of students graduating with STEM degrees. These intervention strategies include facultyinitiated, evidence-based educational opportunities, with a strong emphasis on active learning for students and supportive development for faculty. The research question guiding this paper is: how can involving and developing faculty in grassroots, evidence-based educational interventions lead to sustainable innovations and transformations in STEM-related disciplines?

Research has established that students who take courses that use active learning outperform students in traditional classes and develop a greater conceptual knowledge of the course content, and there is considerable need to develop and support faculty in using active learning techniques $[1,7]$. In this context, faculty development today occurs in the Age of the Network wherein faculty, academic leaders, and faculty developers will need to connect, communicate, and collaborate to meet the challenge of how to do more with less while simultaneously maintaining excellence [12]. A supportive teaching culture provides various forms of 
informative feedback about individual teaching effectiveness in a way that feels safe and non-threatening to individual teachers. The risk associated with this work is minimized when administrative leadership has agreed that the work is important. This supportive approach stimulates motivation to achieve excellence in teaching $[6,10]$.

This is especially significant because most faculty members hold their primary allegiance to their discipline. Thus, there is an increasing emphasis on development of discipline-specific pedagogical knowledge among faculty. Specific strategies for such discipline-centric development include recognizing particular curricular and pedagogic concerns of the disciplines; helping faculty to develop as scholars in the teaching of their discipline; encouraging some faculty to develop careers in the teaching of their discipline; and working with disciplinary organizations to promote discipline-based teaching initiatives [8,9].

Faculty development takes time, and a single workshop is not typically sufficient for deep, transformative change to occur [11]. Incentives for faculty development have typically been provided to encourage them to experiment, implement, or revise courses or curricula [2]. Release time from teaching and other responsibilities is one type of incentive that has been provided to facilitate faculty development [3]. A more comprehensive perspective to faculty incentives links such rewards to the context and strategic directions of the faculty member's respective institution. In this view, incentives for faculty development are aligned with broader priorities of the campus [5].

Faculty consultations with instructional designers and learning technologists are a long-held tradition in faculty development [10]. These consultations include helping faculty develop learning objectives, determining instructional strategies for achievement of those objectives, leveraging active learning and instructional technology effectively, engaging students meaningfully in the class, and evaluating the overall outcomes of a course. Indeed, the type, frequency, and impact of such consultations are one way faculty developers gauge their effectiveness in serving institutional constituents [4].

\section{INVOLVING FACULTY}

Transformative faculty development requires stimulating interest, creating a deep understanding, and assisting with implementation of effective teaching interventions [13]. Thus, CI-STEP developed a program of faculty development activities and supports within a partnership framework that includes incentives, targeted workshops, consultations, and cohort building. This is organized under an initiative known as CI-STEP Mini Grants, which are organized and leveraged to advance and sustain the student-centered initiatives of the CI-STEP project.

CI-STEP project leaders, in partnership with the IUPUI Center for Teaching and Learning, developed the CI-STEP Mini Grants program to support the goals of CI-STEP. The purpose of the mini grants is to provide faculty with support, time, and resources to implement projects designed to improve student learning and success at IUPUI through the CI-STEP initiative. In addition, it is expected that the grants will increase faculty competitiveness for external educational or curricular improvement grants and increase the number of faculty involved in pursuing the scholarship of teaching and learning.

Each mini grant provides funding to faculty members to analyze needs, design courses, develop instructional materials, implement online courses, and evaluate the effectiveness. Funds range from USD \$5,000-\$25,000 per CI-STEP mini grant award, depending on the scope of the project and the number of faculty members involved. Faculty make application for a mini grant through a competitive peer review process, and mini grant applications require the following submission components:

- Cover sheet, including contact information for the faculty member

- Abstract, which summarizes the proposed CI-STEP project

- Key personnel, including the faculty member who is the Principal Investigator on the project

- Project description, which includes the following: Description of course, including enrollment figures; problem statement; rationale and literature review; project goals; proposed interventions; predicted learning outcomes; number of students impacted; and expected impact on enrollment (if applicable).

- Evaluation/assessment plan, including how the overall project effectiveness will be measured

- Dissemination plan, which includes how results of the project will be shared within the IUPUI campus and throughout the broader academic community

- Project timeline, including the milestones for key activities and deliverables

- Budget, which includes the anticipated project expenses and a budget narrative explaining how each expense supports the project goals

In support of the mini grants, targeted workshops are conducted by CI-STEP project leaders, professionals from the IUPUI Center for Teaching and Learning, and other experts on campus and focus on education grant proposal writing, preparing for Institutional Review Board submission and approval process, assessment of student learning, project evaluation, as well as on specific topics related to STEM education, all dependent on the specific needs of the faculty who are awarded mini grants.

In addition to targeted workshops, faculty consultations with instructional designers and learning technologists are a long-held tradition in faculty development. These consultations include helping faculty develop learning objectives, determining instructional strategies for achievement of those objectives, leveraging active learning 
and instructional technology effectively, engaging students meaningfully in the class, and evaluating the overall outcomes of a course. Indeed, the type, frequency, and impact of such consultations are one way faculty developers gauge their effectiveness in serving institutional constituents.

Finally, mini grant awardees meet regularly in order to build an education research community that has a special focus related to STEM education. This faculty 1 community also serves as a context for planning and scheduling workshops to support project work. Eventually, this group of faculty is expected to become leaders of reform STEM education in their respective departments by leading workshops and giving presentations as they disseminate their own work stemming from the mini grants.

\section{SUCCESSFUL STRATEGIES}

Faculty in both the School of Science and the School of Engineering and Technology at IUPUI have been awarded mini grants to implement evidence-based approaches to enhancing learning in STEM disciplines.

Projects funded-to-date include the following:

Summer Industrial Project Program, which has these objectives:

- Promote student retention and persistence in engineering technology by providing real-world engineering experiences.

- Strengthen the relationship between IUPUI and the industrial community

- Provide future employment by the industrial community

Develop a Rigorous Two-Year Mathematics Degree, which has these objectives:

- Offer four 200-level courses in a higher math sequence

- Articulate the Ivy Tech Community College with IUPUI

- Create a two-year degree incorporating the four 200-level courses along with Calculus 1 and Calculus 2

Engineering and Technology Alliance for Retention of Multicultural Students, which has these objectives:

- Create a sense of "I can succeed in Engineering and Technology courses" with the help of using campus resources such as faculty, peers, and tutoring resources

- Create an awareness of "time management / creating a fixed schedule" revolving around interactions of students, school, work, and home schedules

- Create an environment where students will be motivated to attend and complete the seminar

- Provide an environment of retention and mentoring that will increase the success of minority students by providing an oversight seminar
Transfer Student Recruitment and Support, which has these objectives:

- Recruit transfer students to study within engineering and technology fields of study

- Retain transfer students currently studying with engineering and technology fields of study

- Build resources at IUPUI and within in School of Engineering and Technology to support transfer students

Using Inductive Learning Methodology to Reduce Student DFW Rates in Mechanical Engineering Technology's Heat and Power Course, which has these objectives:

- Increase the among of active student learning through inquiry-based problem-solving

- Reduce the number of students earning a D or F or Withdrawing (DFW) from the course

- Replicate the successful practices in other Mechanical Engineering Technology courses

From Studio to Student: E-Mentoring in Computer Graphics Technology, which has these objectives:

- Develop a modern, adaptable model of STEM education delivery that will be a leader in its approach within the School of Engineering and Technology

- Attract, recruit, and retain new and existing students to the Computer Graphics Technology program

- Attract highly talented industry professionals to the Computer Graphics Technology program, whose association will immediate elevate the reputation of the program

Improving the Retention of Freshman Engineering Students through Proactive Peer Mentoring, which has these objectives:

- Increase the retention of freshman engineering students in engineering majors

- Increase the rate at which freshman engineering students complete their first year coursework

Enhancing Student Comprehension in Genetics through Recitation, which has these objectives:

- Decrease DFW rates in the Genetics course

- Increase content knowledge level and depth

- Increase student comprehension of material and better prepare students for future courses

Organic Chemistry Workshop Series, which has these objectives:

- Decrease DFW rates in the Organic Chemistry course

- Increase performance on the American Chemical Society's Organic Chemistry final exam

- Increase student perceptions of the course 
Creating a Physics Learning Space, which has these objectives:

- Develop dedicated space for tutoring, supplemental instruction, and peer mentoring in Physics courses

- Decrease attrition in all introductory Physics courses

\section{CONCLUSIONS-TO-DATE, LESSONS LEARNED, AND IMPLICATIONS}

Of the mini grants awarded, several have reported quantitative data that demonstrate improvement in student performance and persistence. DFW rates have dropped, final exam averages have increased, and attendance has increased at newly-formed STEM resource centers. As importantly, it is clear that mentoring initiatives including peer-led team learning and attendance at both lectures and peer mentoring in gateway courses are making a very positive impact on both students and mentors. Qualitative data in the form of observations, focus groups, and interviews show that mentoring initiatives make a difference in perceptions of students and mentors toward efficacy in STEM core concepts and toward ability to complete a STEM degree. In one largescale mentoring program an unexpected result was that student mentors (upperclassmen and graduate students) reported an interest in STEM teaching as a result of their mentoring experience.

Furthermore, mini grant awardees have pledged to continue the student-centered pedagogies and assessments they developed with the CI-STEP grant resources. Observing student improvement and assessments that produced clear results and the necessary findings to make data-driven decisions, mini-grant awardees expressed willingness to change existing practice and pedagogy and use built-in formative and summative assessment.

While more data must be collected for the CI-STEP project, it is apparent that a culture shift in how to teach STEM to undergraduates is taking place on the IUPUI campus. Data support the fact that the mini-grant program did indeed address the issues of sustained change, faculty buy-in, support for change, and using assessment to make data-driven decisions surrounding student-centered pedagogy. Findings support previous research in these areas, and the fact that the CI-STEP program continues to gather data and meet original goals and objectives is further testimony to the value of mini-grants to jump-start sustained faculty change. The key elements of the CI-STEP project that led to success included the process of developing and awarding the mini grants. In replicating some of the aspects of the mini grant process in other contexts to support faculty development in STEM disciplines, the following recommendations are noted.

First, an institutional strategy for STEM education and faculty development is needed. This includes determining the institution's approach to STEM education, the programs and services it desires to offer students and faculty alike, and the infrastructure to be created or leveraged in support of faculty development for STEM.

Second, senior level commitment to faculty development is needed. This includes an appreciation for the knowledge, skills, experiences, and perspectives faculty members bring to the provision of the teaching and learning process, along with an understanding that targeted, sustained, and appropriate faculty development interventions are needed on an ongoing basis-especially salient for rapidly-changing STEM disciplines.

Third, allocation of appropriate resources to support faculty development is needed. This includes the physical, human, and financial capital needed to support faculty in their teaching and learning endeavors, and includes spaces for faculty to gather and receive support, the use of peer consultants and others to provide guidance and assistance to faculty members, and the financial resources to invest in faculty development.

Finally, a framework to support partnerships in faculty development is needed. This includes the appropriate programs and interventions to facilitate faculty development, including an initiative such as the CI-STEP mini grants process, which builds capacity for faculty teaching in online contexts, provides partnership opportunities between faculty developers and faculty members, and makes a contribution to a broader institutional goal of supporting online teaching and learning.

The CI-STEP project is concluding its work in 2015. However, the investment in faculty development, administered through mini grants that were proposed by faculty, holds the promise of sustaining and scaling the initial investment by CI-STEP. Future research is needed to determine the outcomes and impact of the various mini grant projects described above, along with an understanding of the structures, incentives, and ongoing supports needed for faculty to continue to adopt evidence-based educational practices in their STEM course. As the summative evaluation of CI-STEP commences this year, this information will be collected, analyzed, and disseminated at a future date.

\section{REFERENCES}

[1] Astin, A. W. (1993). What Matters in College? Four Critical Years Revisited. San Francisco: Jossey-Bass.

[2] Baldwin, R.G. (1986). Incentives for Faculty Vitality. San Francisco: Jossey-Bass.

[3] Boice, R. (1987). Is release time an effective component of faculty developed programs? Research in Higher Education, (26)3, 311-326.

[4] Chism, N.V.N. and Szabo, B. (1997). How faculty development programs evaluate their services. Journal of Staff, Program, and Organization Development, (15)2, 55-62.

[5] Diamond, R.M. (1999). Aligning Faculty Rewards with Institutional Mission: Statements, Policies \& Guidelines. Bolton: Anker.

[6] Feldman, K.A. and Paulsen, M.B. (1999). Faculty motivation: The role of a supportive teaching culture. New Directions for Teaching and Learning. San Francisco: Jossey-Bass.

[7] Hake, R. R. (1998). Interactive-engagement versus traditional methods: A six-thousand student survey of mechanics test data for introductory physics courses. American Journal of Physics, 66:64-74. 
[8] Jenkins, A. (1996). Discipline-based educational development. International Journal for Academic Development, 1(1), 50-62.

[9] Lenze, L.F. (1996). Discipline-specific faculty development. NEA Higher Education Center Update, 2(3).

[10] Lewis, K.G. (1996). Faculty development in the United States: A brief history. International Journal for Academic Development, (1)2, 26-33.

[11] Millard, D. L. (2011). Transforming Undergraduate Education in STEM: Making and measuring impacts. Presented at the 2011
CCLT/TUES Principal Investigators (PIs) Conference), Washington, DC

[12] Sorcinelli, M. D., Austin, A. E., Eddy, P. I., and Beach, A. L. (2006). Creating the Future of Faculty Development: Learning From the Past, Understanding the Present. Bolton, MA: Anker.

[13] Varma-Nelson, P. (2006). Peer-Led Team Learning. Metropolitan Universities Journal, 17(4), 19-29. 